\title{
Use Design or Technology: the Antique Römer Glass
}

\author{
A. DARABOS ${ }^{1}$, J. SZALAI ${ }^{2}$ \\ ${ }^{1}$ Budapest University of Technology and Economics , Faculty of Mechanical Engineering, Department of of \\ Machine and Product Design, darabos.anita@gt3.bme.hu \\ 2Budapest University of Technology and Economics , Faculty of Mechanical Engineering, Department of of \\ Machine and Product Design, judit.szalai@gt3.bme.hu
}

\section{Introduction}

In this paper, the Römer-glass are assessed as indicator of the technology and design by using a comparative method. We identifed their designing technology methods and associated them with manufacturing centres. All of them made from green forest glass and produced in northwestern and central Europe from around 1000-1700 AD. The Römer glass present dining traditions and habits in the middle ages, furthermore like a personal belongings can be associated with the presentation of social status or individual expression.

\section{The history of green forest glass}

Looking at the history of glass production, it can be said that the forest huts and manufactures of Central Europe were active throughout the Middle Ages. This involved the region having the necessary natural resources - wood material requirement for glass production is significant (eight kilograms of wood needed to produce one kilogram of glass). Moreover, pure river sand was directly available, in addition - due to the proximity of the rivers - other raw materials could be easily transported. The soda for glass production was replaced by potash with heavy potassium carbonate in wood (Figure 1). [1] The glasses were made from raw materials of low-cost purity, especially the iron oxide content of the sand. The result was greenish, greenish-brownish shades in glass, and therefore the products here were known as Waldglas, in the Middle Ages.

\subsection{The types of forest glass}

The quantity of glassware and the number of types grew steadily in period of the 15th century. The type of wine glass were mostly decorated with plastic elements. Widely used technique was the glass drops application on glass surfaces.

\subsubsection{The type of Maigelein drinking bowl}

One of the most common glass forms of the 15th century was the Maigelein drinking bowl from green forest glass, which was a small, low hollow cup with a conical base. The lightly rounded wall of the glass is decorated with spiral crosses, diamonds or basket patterns. 
The pattern was created directly as the hot glass was inflated into a decorative clay pattern as a negative mold. [2]

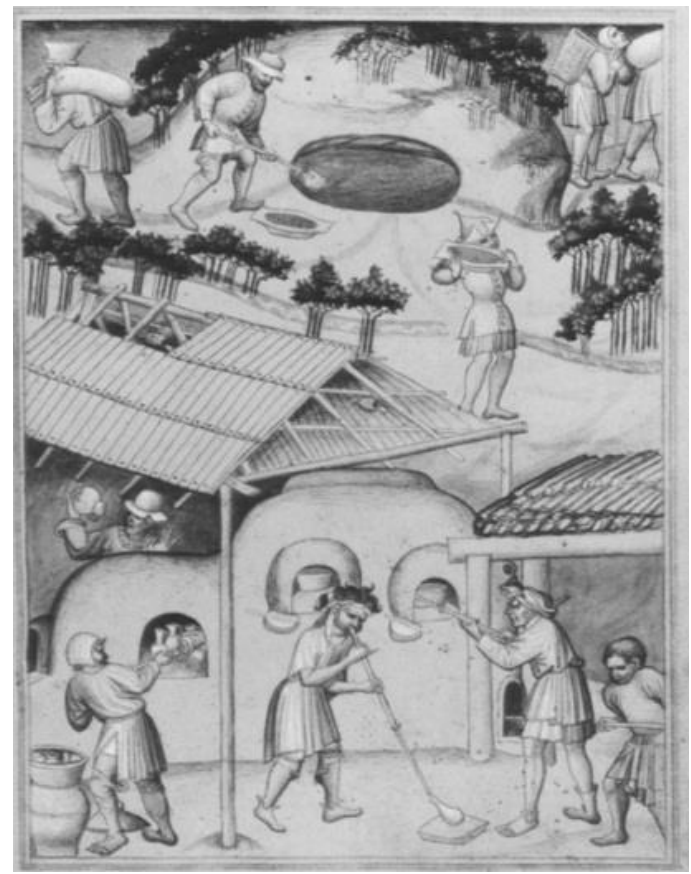

Figure 1. Representation of a Medieval Forest Glass hut. In the background, wood ash is burned and transported. [1]

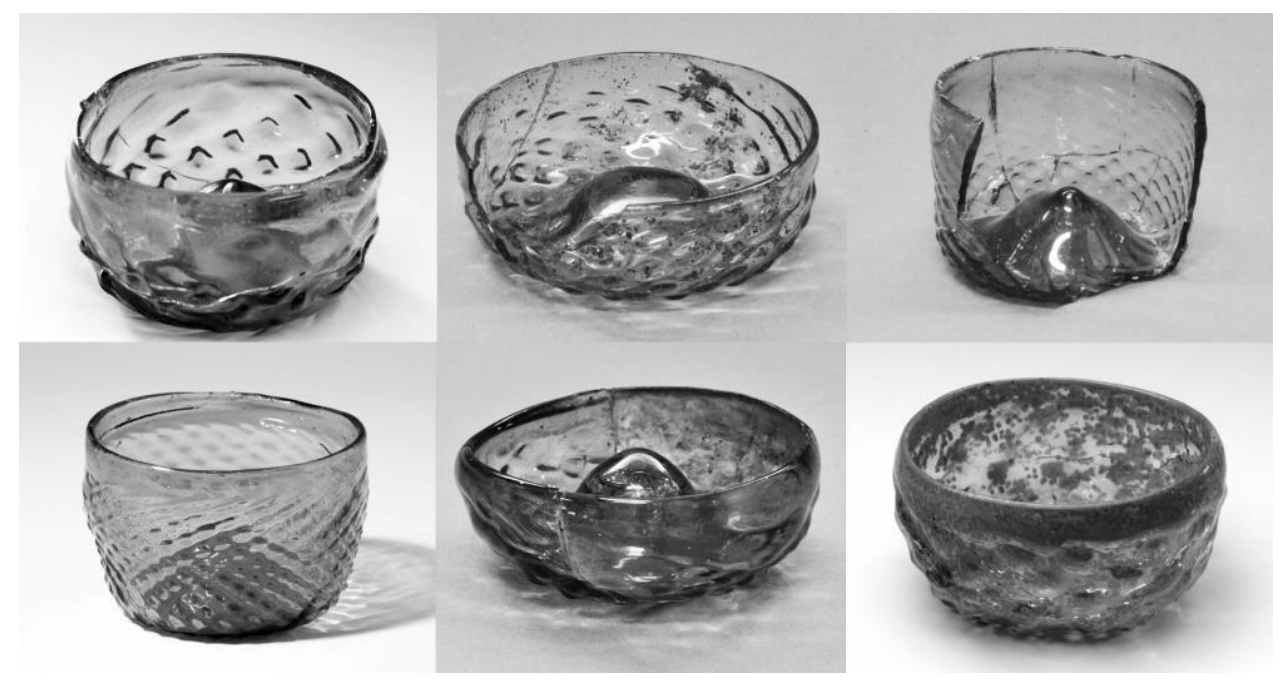

Figure 2. The type of Maigelein drinking bowls with optical decorations[2]

It is a forest glass, the lower half of which is decorated with pulled glass drops, known as 'thorn knobs', and which spreads out into a conical bowl. (Figure 3.) [3]

\subsubsection{The type of Krautstrunk prunted beaker}

A type of prunted beaker with a cup-shaped mouth and a cylindrical or barrel shaped body decorated with prunts, known as a Krautstrunk or "cabbage stalk" or „berkemeier” in Netherlands, (one can be found in the Still Life with Gilded Cup by Willem Claesz [3]), was a popular drinking glass in the sixteenth and the first half of the seventeenth century. 


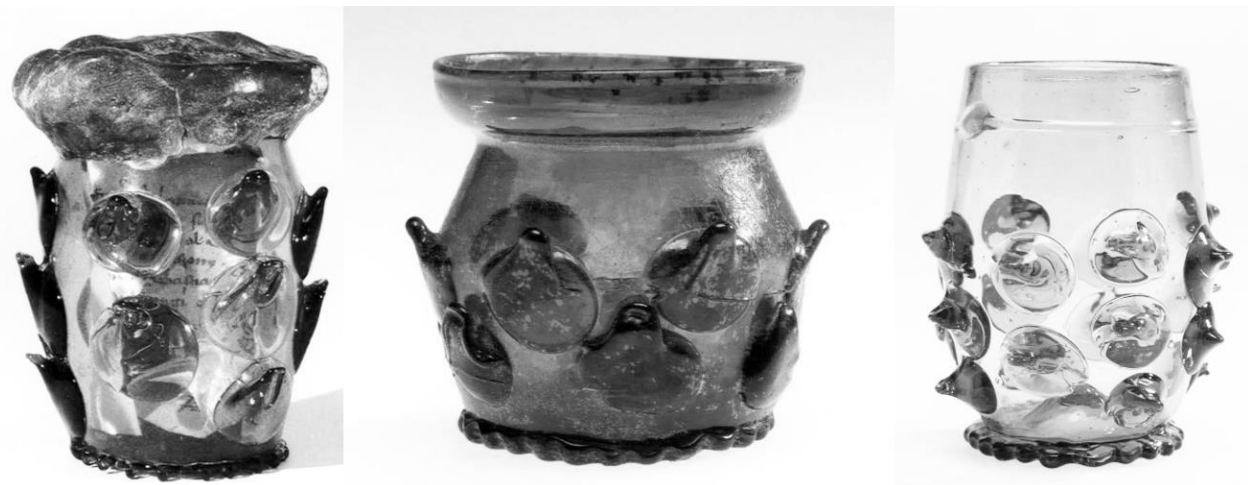

Figure 3. The type of Krautstrunk prunted beaker with the glass drops [2]

\subsubsection{The type of Stangenglas}

A tall, narrow cylindrical drinking vessel (hence the name "pole glass"), usually with a pedestal foot (Figure 4.)[4]
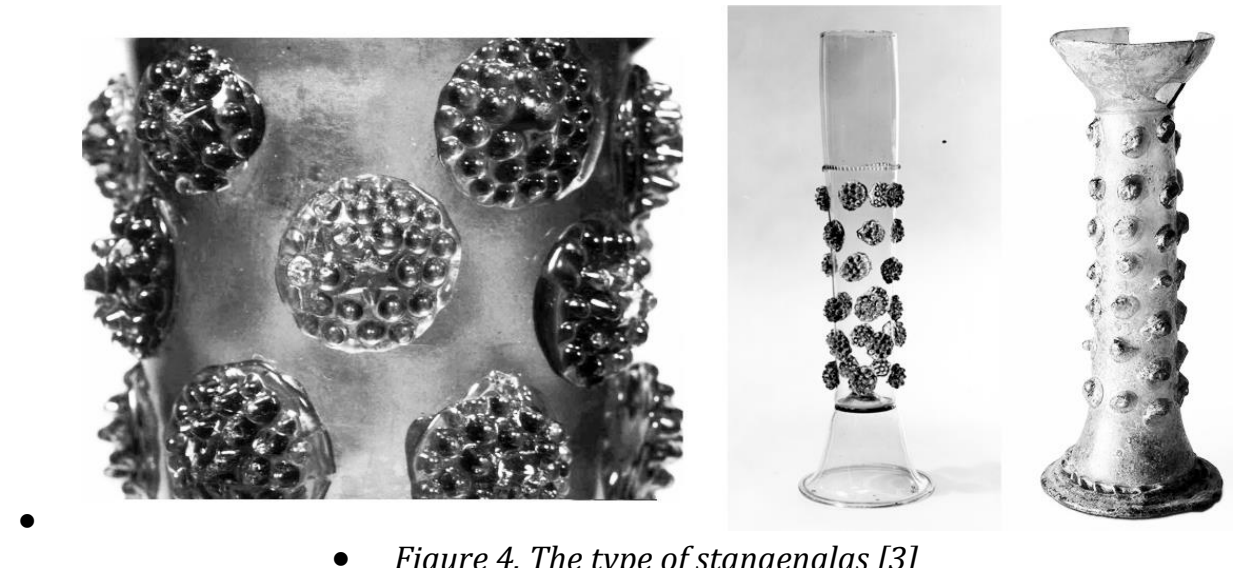

- $\quad$ Figure 4. The type of stangenglas [3]

\subsection{The type of Römer glass}

The Römer glass reaching perfection in the 17th century. The shape of the Römer is a hemisphere superimposed on a cylinder, with a hollow foot built up by coiling threads of molten glass around a conical core. From the seventeenth century the shape of Römer glass becomes rounded, and the drops forms are no longer applied to the trunk. The decorated glasses with the engraved image or text, they are more frequent in museums, because they had a rare added value. (Figure 6-7.) [5]

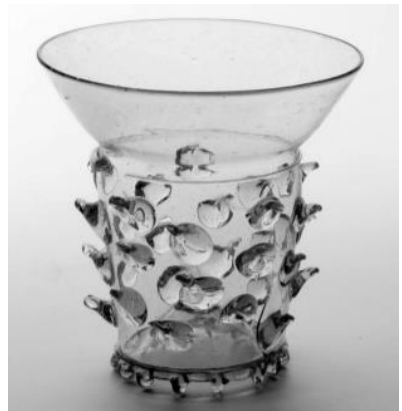

Figure 5. The type of Berkemeier glass[4]

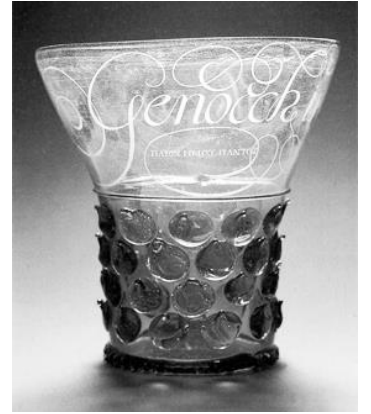

Figure 6. Engraved Römer glass[5] 


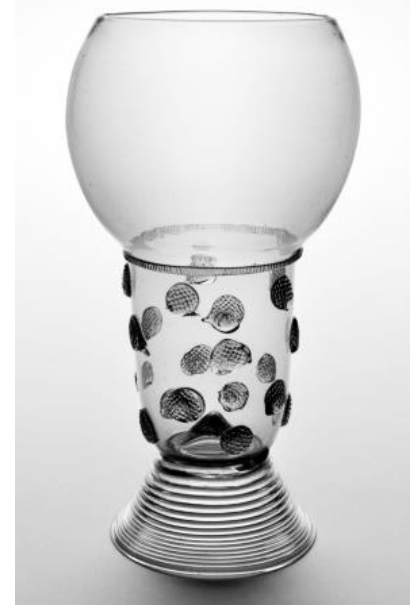

Figure 7. The type of Römer glass[6]

\section{Design generated by human hand deformations in middle ages}

The hand grip strength in both hands was affected by the size of the hand and the grip of the hand grip of the utility object. These findings reveal that medieval glass objects made by medieval glass workers have been optimized for contemporary craftsmen by their formal design, grip efficiency, and manual contact. In this case, examining the surface designs, analyzing the effect of the hand on the optimum adhesion range, it is recognized that the applied decorative elements help to hold the fingers of the hand when using the object, ensuring a firm adhesion to applied surface elements.

\subsection{The hand grip force and grip control force}

The hand grip force and grip control force are two predictions of the function of the upper limb to accomplish daily activities. The hand size and the diameter of the hand grip used alone influence the hand grip force. Medieval weapons of the time, "cheap" tools were simply machined. The large number of infantry was supplied with these weapons. Hard heavy swords and bards were, by their very weight, dangerous devices. As the study area is considered to be the reconstruction focus point of the contemporary design process, the exploration of the knowledge can also be interpreted as an important point in exploring the process of creating objects of utility. The grip, the size and diameter of the drinking pots of the same age evoke arms shapes.

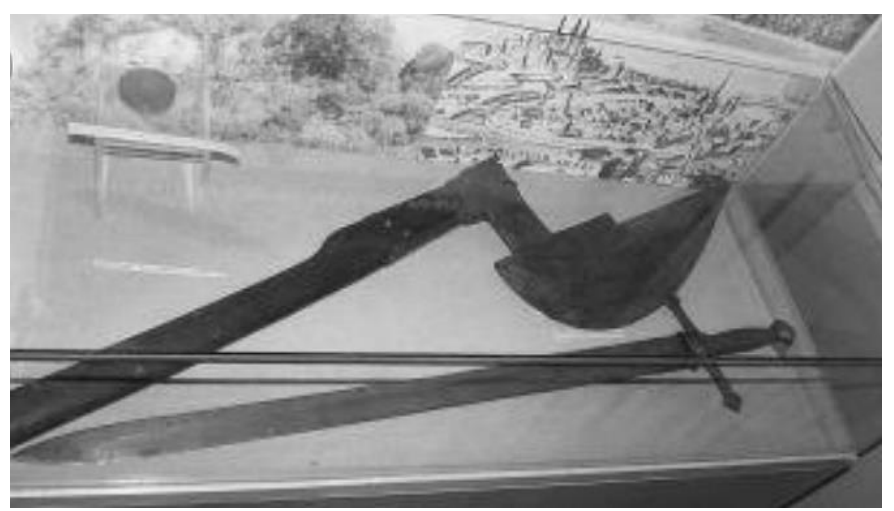

Figure 8. Swords and bards [7] 
When examining anthropological data, the special ergonomic requirements highlight the importance of applying the aforementioned form design, the use of additional formatting to facilitate use, and textured surfaces. (Figure 8.) [8]

\subsubsection{Examination of touch sensing during hand grid}

The examination of the surface tactile sensation of glass cups, cups and cups points out that during the marking loading of the fingerprints, partial overlaps on the glass surface without the use of partial surface grooves occur at the periphery of the finger-to-eye contact before the hand is completely sliced out.

\section{Conclusions}

The assessment of the human slip sensing capability indicates that on smooth transparent surfaces, the glass objects shown above, could have been able to prevent slipping in the hands when on average only $40 \%$ of the contact surface was a completely smooth glass surface. We also point out that the use of partial textures and surface form elements made it possible for the hand to have a more accurate slip detection. Finally, it can be stated that, in addition to the constant force of normal contact, when the surface elements obstructed by slipping have been used, it significantly increased the contact friction and thus the amount of momentary deformation of the fingertips. Assumed, these results show that full and partial surface texture patterns of the exposed period are important to the slip recognition of the hand and support the assumption that the central nervous system is relied upon when it is used to attach the force of the subject when using the object.

\section{References}

[1] C. Hess - T. Husband: European Glass in the J. Paul Getty Museum: Catalogue of the Collections. 33-35.

[2] The Corning Museum of Glass, 2018.10.10.

[3] Rijkmuseum, Amsterdam, Netherlands www.rijkmuseum.nl, 2018.10.10.

[4] British Museum, http://www.britishmuseum.org/ 2018.10.10.

[5] Historisches Museum Basel, http://www.hmb.ch 2018.10.10.

[6] Museum Boijmans Van Beuningen, Rotterdam, http://www.boijmans.nl 2018.10.10.

[7] The Museum of Fine Arts, Houston https://www.mfah.org 2018.10.10.

\section{Acknowledgement}

The research reported in this paper was supported by the Higher Education Excellence Program of the Ministry of Human Capacities in the frame of Artificial intelligence research area of Budapest University of Technology and Economics (BME FIKP-MI). 